\title{
Advances in the management of idiopathic pulmonary fibrosis
}

\section{Jay H Ryu* and Craig E Daniels}

\author{
Address: Division of Pulmonary and Critical Care Medicine, Mayo Clinic College of Medicine, 200 1st Street SW, Rochester, MN 55905, USA \\ *Corresponding author: Jay H Ryu (ryu.jay@mayo.edu) \\ Fl000 Medicine Reports 2010, 2:28 (doi:10.3410/M2-28)
}

The electronic version of this article is the complete one and can be found at: http://fl000.com/reports/medicine/content/2/28

\begin{abstract}
Idiopathic pulmonary fibrosis (IPF) is a common form of interstitial lung disease and usually results in progressive respiratory insufficiency and death. Steady progress has been made in understanding the pathogenesis of IPF and multiple clinical trials are ongoing, but effective therapy remains elusive.
\end{abstract}

\section{Introduction and context}

Idiopathic pulmonary fibrosis (IPF) is the most common form of interstitial lung disease and occurs predominantly in middle-aged and older adults. It is defined by the histopathologic pattern of usual interstitial pneumonia occurring in the absence of an identifiable cause of lung injury such as drug toxicity, inhalational agents, connective tissue disease, and so on [1-3]. Median survival time following diagnosis of IPF is 2-3 years [2-5]. Although consensus has been achieved in the definition of this disorder and advances have occurred in our understanding of the mechanisms of lung fibrosis, effective therapy has remained elusive.

The cause of IPF remains unknown. Developing knowledge of the pathogenesis of IPF has shifted focus towards the role of epithelial injury, dysregulated wound healing, and fibrosis and away from inflammation as the predominant pathologic process $[6,7]$. Thus, the search for effective therapeutic agents for the treatment of IPF has also shifted to agents with antifibrotic properties and away from anti-inflammatory treatments [8]. In addition, there is growing interest in vasomodulators to treat pulmonary hypertension, which commonly occurs in patients with IPF, as well as pulmonary rehabilitation to improve the quality of life of these patients $[9,10]$.

\section{Recent advances \\ Pharmacologic agents}

Traditional therapy for IPF has used glucocorticoids in conjunction with azathioprine or cyclophosphamide with the aim of reducing inflammation in the lung parenchyma as dictated by the previous paradigm [5]. This approach is associated with drug-related adverse effects and efficacy has never been validated.

\section{Gamma-interferon}

Gamma-interferon caused excitement as a treatment for IPF when Ziesche and colleagues [11] reported dramatic improvement in an open, randomized trial of 18 IPF patients. This initial enthusiasm was tempered when a randomized, double-blind, placebo-controlled clinical trial of 330 IPF patients showed no difference between placebo and gamma-interferon groups in progression-free survival, pulmonary function, or quality of life outcome measures [12]. A third study evaluated the role of gamma-interferon therapy in selected IPF patients with mild-to-moderate physiological impairment ('early disease') and also failed to show improved survival [13]. Gamma-interferon therapy is not recommended in the treatment of IPF.

\section{N-Acetylcysteine}

$\mathrm{N}$-Acetylcysteine (NAC) is an antioxidant available in an oral form with or without a prescription. In a study of IPF patients treated with prednisone and azathioprine the addition of NAC compared to placebo was associated with a slower deterioration in forced vital capacity and single breath carbon monoxide diffusing capacity at 12 months [14]. However, the measured functional benefit was rather modest. In addition, the absence of placebo control in this study makes interpretation of these results uncertain. 


\section{Etanercept}

A tumor necrosis factor-alpha antagonist, etanercept (a recombinant soluble human tumor necrosis factor receptor), was investigated in a clinical trial exploring its possible role in the treatment of IPF. Etanercept therapy was well tolerated but no differences were noted in the primary endpoints, including changes from baseline in forced vital capacity (percent predicted), diffusing capacity for carbon monoxide (percent predicted), and alveolararterial oxygen gradient at 48 weeks [15].

\section{Pirfenidone}

Pirfenidone is a pyridone compound with broad antifibrotic properties. In a double-blind, randomized, placebo-controlled trial involving 107 subjects, no significant difference was seen in the primary endpoint of the change in the lowest oxygen saturation by pulse oximetry during a 6-minute exercise test between baseline and 9 months [16]. However, pirfenidone therapy was associated with a smaller decline in vital capacity and reduced incidence of acute exacerbations. In a subsequent trial (275 subjects) that employed change in vital capacity as the primary endpoint, pirfenidone therapy was associated with a decreased rate of decline in vital capacity and increased progression-free survival time (a secondary endpoint). A manuscript describing the results of this study has been published online [17]. Pirfenidone is currently under review by the US Food and Drug Administration for use in the treatment of IPF.

\section{Imatinib}

Imatinib is a tyrosine kinase inhibitor that has been shown to inhibit lung fibrosis in bleomycin models of pulmonary fibrosis. A randomized clinical trial of 119 patients with mild-to-moderate IPF failed to show a favorable effect on survival or lung function [18]. There was a significant dropout rate in this study, which may have been underpowered. It remains unclear whether other tyrosine kinase inhibitors may have a role in the treatment of IPF.

\section{Anticoagulant therapy}

In 2005, Kubo and colleagues reported prednisolone plus anticoagulant therapy was associated with a marked reduction in mortality in patients with acute exacerbation of IPF compared to those on prednisolone alone. However, this was an unblinded study that included a relatively modest number of patients (56 subjects) and had a $26 \%$ dropout rate in the anticoagulant arm of the study. It is possible that anticoagulant therapy may have a role in the treatment of IPF since parenchymal injury in IPF may be associated with pulmonary vascular microthrombi and IPF patients are at risk for venous thromboembolism. Therefore, a multicenter clinical trial investigating the use of anticoagulant therapy has been initiated within the National Institutes of Health (NIH)sponsored IPF Clinical Research Network. At the present time, we do not recommend the use of anticoagulant therapy in the treatment of IPF.

\section{Vasomodulatory agents}

Pulmonary hypertension is a relatively common complication of IPF and adversely affects prognosis [9,20-23]. Increasing numbers of vasomodulatory agents have become available in recent years and some of these agents have been studied in IPF patients with pulmonary hypertension [24]. In a double-blind, randomized clinical trial, bosentan therapy failed to show superiority over placebo on 6-minute walk distance but did demonstrate a trend toward delayed time of death or disease progression, and improvement in quality of life measures. Results of another bosentan study, BUILD-3 (Bosentan Use in Interstitial Lung Disease 3), are pending. In an open-label study of 14 IPF patients, sildenafil therapy improved 6-minute walk distance and was welltolerated [25]. A multicenter clinical trial on the effects of sildenafil therapy was recently completed in the NIH-sponsored IPF Clinical Research Network and the results are pending. Based on the data available to date, bosentan and sildenafil are not recommended in the treatment of IPF patients with pulmonary hypertension.

\section{Other management modalities}

Although there are no high-quality data demonstrating the benefit of supplemental oxygen therapy for patients with IPF, it is prudent to provide supplemental oxygen therapy for those with resting hypoxemia or significant oxygen desaturation with exercise on room air. In such patients supplemental oxygen therapy likely provides benefit in symptoms and quality of life. Other supportive measures to be addressed include optimization of the nutritional status and updating of immunizations.

Deconditioning is a common problem for IPF patients, particularly those with advanced disease, and can exacerbate functional and psychosocial impairments. Pulmonary rehabilitation can improve symptoms, walk distance, and quality of life [10].

The role of gastroesophageal reflux and acid aspiration in the pathogenesis of IPF remains unsettled [26]. It is reasonable to treat IPF patients who have symptomatic gastroesophageal reflux with acid-suppressive medications and anti-reflux measures. Fundoplication may be indicated in IPF patients with persistent gastroesophageal reflux symptoms or esophagitis who fail medical therapy or in those likely to undergo lung transplantation. 
Lung transplantation in IPF is associated with a 5-year survival rate of $40-50 \%[27,28]$. Appropriate patients with IPF should be offered an opportunity for lung transplant evaluation without undue delay since those with IPF have excess mortality compared to patients with other lung diseases awaiting lung transplantation.

\section{Implications for clinical practice}

In the absence of strong evidence favoring the use of any pharmacologic agent in the treatment of IPF, clinicians and patients need to reach an informed decision regarding possible management options. None of the currently available pharmacologic agents is supported by enough evidence to warrant their routine clinical use. In those patients who wish to undergo a trial of pharmacologic therapy, options include NAC monotherapy and NAC combined with prednisone and azathioprine. Pirfenidone may also prove to be a reasonable option, if it becomes available. Whenever possible, patients with IPF should be offered participation in ongoing clinical trials in order to identify effective treatments for IPF. Those patients who are appropriate candidates for lung transplantation should be referred promptly for an evaluation since the clinical course of IPF can be unpredictable, (e.g., acute exacerbation).

\section{Abbreviations}

IPF, idiopathic pulmonary fibrosis; NAC, N-acetylcysteine; NIH, National Institutes of Health.

\section{Competing interests}

The authors declare that they have no competing interests.

\section{Acknowledgements}

JHR and CED both receive funding from the National Institutes of Health.

\section{References}

I. Katzenstein AL, Myers JL: Idiopathic pulmonary fibrosis: clinical relevance of pathologic classification. Am J Respir Crit Care Med 1998, I57:1301-15.

2. Ryu JH, Colby TV, Hartman TE: Idiopathic pulmonary fibrosis: current concepts. Mayo Clin Proc 1998, 73:I085-I0I.

3. American Thoracic Society; European Respiratory Society: American Thoracic Society/European Respiratory Society International Multidisciplinary Consensus Classification of the Idiopathic Interstitial Pneumonias. This joint statement of the American Thoracic Society (ATS), and the European Respiratory Society (ERS) was adopted by the ATS board of directors, June $200 \mathrm{I}$ and by the ERS Executive Committee, June 200 I. Am J Respir Crit Care Med 2002, I65:277-304. Erratum in Am J Respir Crit Care Med 2002, 166:426.

4. Bjoraker JA, Ryu JH, Edwin MK, Myers JL, Tazelaar HD, Schroeder DR, Offord KP: Prognostic significance of histopathologic subsets in idiopathic pulmonary fibrosis. Am J Respir Crit Care Med 1998, I57:199-203.

5. American Thoracic Society; European Respiratory Society: Idiopathic pulmonary fibrosis: diagnosis and treatment. International consensus statement. Am J Respir Crit Care Med 2000, 1 6 1:646-64.

6. Selman M, King TE, Pardo A: Idiopathic pulmonary fibrosis: prevailing and evolving hypotheses about its pathogenesis and implications for therapy. Ann Intern Med 200I, I34:I36-5I.

7. du Bois RM: Strategies for treating idiopathic pulmonary fibrosis. Nat Rev Drug Discov 2010, 9:129.

8. Walter N, Collard HR, King TE Jr: Current perspectives on the treatment of idiopathic pulmonary fibrosis. Proc Am Thorac Soc 2006, 3:330-8.

9. Behr J, Ryu JH: Pulmonary hypertension in interstitial lung disease. Eur Respir J 2008, 3 I: | 357-67.

10. Swigris JJ, Brown KK, Make BJ, Wamboldt FS: Pulmonary rehabilitation in idiopathic pulmonary fibrosis: a call for continued investigation. Respir Med 2008, 102:1675-80.

II. Ziesche R, Hofbauer E, Wittmann K, Petkov V, Block LH: A preliminary study of long-term treatment with interferon gamma-Ib and low-dose prednisolone in patients with idiopathic pulmonary fibrosis. N Engl J Med 1999, 34I:I264-69.

12. Raghu G, Brown KK, Bradford WZ, Starko K, Noble PW, Schwartz DA, King TE Jr: A placebo-controlled trial of interferon gamma-I $b$ in patients with idiopathic pulmonary fibrosis. N Engl J Med 2004, 350: I 25-33.

13. King TE Jr, Albera C, Bradford WZ, Costabel U, Hormel P, Lancaster L, Noble PW, Sahn SA, Szwarcberg J, Thomeer M, Valeyre D, du Bois RM; INSPIRE Study Group: Effect of interferon gamma-Ib on survival in patients with idiopathic pulmonary fibrosis (INSPIRE): a multicentre, randomised, placebocontrolled trial. Lancet 2009, 374:222-8.

Changes Clinical Practice

FI000 Factor 6.4 Must Read

Evaluated by Vincent Cottin 10 Aug 2009, Stephen Frankel 02 Sep 2009

14. Demedts M, Behr J, Buhl R, Costabel U, Dekhuijzen R, Jansen HM, MacNee W, Thomeer M, Wallaert B, Laurent F, Nicholson AG, Verbeken EK, Verschakelen J, Flower CD, Capron F, Petruzzelli S, De Vuyst $P$, van den Bosch JM, Rodriguez-Becerra E, Corvasce G, Lankhorst I, Sardina M, Montanari M; IFIGENIA Study Group: Highdose acetylcysteine in idiopathic pulmonary fibrosis. $N$ Engl J Med 2005, 353:2229-42.

15. Raghu G, Brown KK, Costabel U, Cottin V, du Bois RM, Lasky JA Thomeer M, Utz JP, Khandker RK, McDermott L, Fatenejad S: Treatment of idiopathic pulmonary fibrosis with etanercept: an exploratory, placebo-controlled trial. Am J Respir Crit Care Med 2008, I 78:948-55.

FI000 Factor 3.0 Recommended Evaluated by Anders Eklund 12 Sep 2008

16. Azuma A, Nukiwa T, Tsuboi E, Suga M, Abe S, Nakata K, Taguchi Y, Nagai S, Itoh H, Ohi M, Sato A, Kudoh S: Double-blind, placebocontrolled trial of pirfenidone in patients with idiopathic pulmonary fibrosis. Am J Respir Crit Care Med 2005, I 7 I: 1040-7.

17. Taniguchi H, Ebina M, Kondoh Y, Ogura T, Azuma A, Suga M, Taguchi Y, Takahashi H, Nakata K, Sato A, Takeuchi M, Raghu G, Kudoh S, Nukiwa T; Pirfenidone Clinical Study Group in Japan: Pirfenidone in idiopathic pulmonary fibrosis. Eur Respir J 2009, [Epub ahead of print].

18. Daniels CE, Lasky JA, Limper AH, Mieras K, Gabor E, Schroeder DR; Imatinib-IPF Study Investigators: Imatinib treatment for idiopathic pulmonary fibrosis: randomized placebo-controlled trial results. Am J Respir Crit Care Med 2010, I8 I:604-10.

19. Kubo H, Nakayama K, Yanai M, Suzuki T, Yamaya M, Watanabe M, Sasaki H: Anticoagulant therapy for idiopathic pulmonary fibrosis. Chest 2005, I 28: |475-82. 
20. Nadrous HF, Pellikka PA, Krowka MJ, Swanson KL, Chaowalit N, Decker PA, Ryu JH: Pulmonary hypertension in patients with idiopathic pulmonary fibrosis. Chest 2005, I 28:2393-9.

21. Lettieri CJ, Nathan SD, Barnett SD, Ahmad S, Shorr AF: Prevalence and outcomes of pulmonary arterial hypertension in advanced idiopathic pulmonary fibrosis. Chest 2006, I 29:74652.

22. Nathan SD, Noble PW, Tuder RM: Idiopathic pulmonary fibrosis and pulmonary hypertension: connecting the dots. Am J Respir Crit Care Med 2007, I 75:875-80.

23. Zisman DA, Ross DJ, Belperio JA, Saggar R, Lynch JP 3rd, Ardehali A, Karlamangla AS: Prediction of pulmonary hypertension in idiopathic pulmonary fibrosis. Respir Med 2007, I 0 I:2 I53-9.

24. King TE Jr, Behr J, Brown KK, du Bois RM, Lancaster L, de Andrade JA, Stahler G, Leconte I, Roux S, Raghu G: BUILD-I: a randomized placebo-controlled trial of bosentan in idiopathic pulmonary fibrosis. Am J Respir Crit Care Med 2008, I 77:75-8I.
25. Collard HR, Anstrom KJ, Schwarz MI, Zisman DA: Sildenafil improves walk distance in idiopathic pulmonary fibrosis. Chest 2007, I 3 1:897-9.

FI000 Factor 3.0 Recommended Evaluated by Jay H Ryu 09 May 2007

26. Raghu G, Freudenberger TD, Yang S, Curtis JR, Spada C, Hayes J, Sillery JK, Pope CE 2nd, Pellegrini CA: High prevalence of abnormal acid gastro-oesophageal reflux in idiopathic pulmonary fibrosis. Eur Respir J 2006, 27:136-42.

27. Thabut G, Mal H, Castier $Y$, Groussard O, Brugiere $O$, MarrashChahla R, Leseche G, Fournier M: Survival benefit of lung transplantation for patients with idiopathic pulmonary fibrosis. J Thorac Cardiovasc Surg 2003, I 26:469-75.

28. Keating D, Levvey B, Kotsimbos T, Whitford H, Westall G, Williams T, Snell G: Lung transplantation in pulmonary fibrosis: challenging early outcomes counterbalanced by surprisingly good outcomes beyond I 5 years. Transplant Proc 2009, 4 I:289-91. 